\title{
An Efficient Polymerase Chain Reaction Approach for the Quantitation of Multiple RNAs in Human Tissue Samples
}

\author{
Adrian Puntschart, Kristin Jostarndt, Hans Hoppeler, and Rudolf Billeter
}

Department of Anatomy, University of Berne, 3012 Bern, Switzerland

\begin{abstract}
We describe a PCR quantitation approach that we have set up to study gene expression in human skeletal muscle biopsies. It is characterized by the independent standardization of the individual steps and ignores attempts to control for the efficiency of the PCR. Different RNA extraction/ reverse transcription efficiencies are normalized by the addition of an unrelated cRNA. Quantitation is achieved by parallel amplifications of reference samples containing known amounts of PCR products. Precision was achieved by multiple measurements of several samples. Our approach allows for the detection of less than twofold differences (27$88 \%$, depending on the RNA species studied) among samples. A comparison of biopsies from highly trained endurance runners with biopsies from untrained subjects showed that the increased mitochondrial density in the runners' samples is accompanied by a proportional increase in the concentration of the MRNA of $c y$ tochrome c oxidease subunit IV.
\end{abstract}

S keletal muscle adapts to changes in activity by alterations in structural components such as myofibrillar protein isoforms as well as its metabolic profile. Many of these adaptations are accompanied by up- or down-regulation in the expression of the respective genes (for review, see ref. 1). Most data on activityinduced changes in gene expression have been obtained from animal models. Our interest is the effect of endurance exercise on human skeletal muscle, in particular the changes in the concentration of specific RNAs elicited by the adaptation process. The description of such changes requires a method that: (1) allows quantitation of RNAs from needle biopsies; (2) permits the efficient analysis of several RNA species in the same sample; (3) enables the discrimination of small differences (twofold or less), and (4) permits parallel processing of numer ous samples for every RNA to account for the interindividual variations among human subjects.

The limited amount of starting material from these biopsies $(10-30 \mu \mathrm{g}$ total RNA from 50-100 $\mathrm{mg}$ tissue) favored the use of the PCR. ${ }^{(2)}$ By way of the exponential amplification of a specific target DNA it offers unsurpassable sensitivity. But this exponential process causes small differences in the efficiency of the amplification process to have a large effect on the amount of product accumulated after a limited number of cycles. ${ }^{(3)}$ This has rendered the quantification of input DNA or cDNA difficult. Numerous methods have been described to control for this inescapable variation of the efficiency, such as competitive PCR, ${ }^{(3)}$ regression analysis of PCR kinetics, ${ }^{(4)}$ or internal $^{(5)} /$ external ${ }^{(6)}$ standards (for review, see refs. 7 and 8 ).
We describe an alternative PCR approach that allows for accurate quantification of RNAs without rigorously controlling for efficiency. The proposed procedure is based on the idea that a single PCR run can be considered an indepenent outcome of a stochastic process with small inevitable differences in reaction efficiencies, ${ }^{(7,9)}$ therefore, it should be possible to treat the variations generated in such a stochastic process by a statistical quantitation approach. That is, it should be possible to process multiple samples and to perform multiple PCR reactions to obtain statistically significant values.

The assessment of the precision of this approach on a series of test experiments demonstrated that we can detect less than twofold differences in the concentrations of particular RNAs. A comparison of biopsies from highly trained endurance runners with biopsies from untrained subjects showed that the increased mitochondrial density in the runners' samples is accompanied by a similar increase in the concentration of the mRNA of cytochrome $c$ oxidase subunit IV.

\section{MATERIALS AND METHODS Samples (Biopsies)}

The PCR test series were done on an autopsy sample from a 26-year-old male, taken from $m$. vastus lat., $20 \mathrm{hr}$ post mortem. Biopsies from $m$. vastus lat. of four endurance trained and four untrained subjects were taken by the Bergström needle technique. All muscle samples were immediately frozen in liquid nitrogen-cooled isopentane, and stored under liquid nitrogen. 


\section{Primers}

The following primer locations were chosen: CLC (chicken myosin light chain partial gene sequence, GenEMBL AC X00460); 5' primer: bases 4022-4050; 3 ' primer: bases 4285-4258; expected PCR fragment; 263 bp. COX4 (human cytochrome $c$ oxidase subunit IV cDNA, GenEMBL AC M34600); 5' primer: bases 322-349; 3' primer: bases 489-463; expected PCR fragment: 168 bp. $28 \mathrm{~S}$ (human $28 \mathrm{~S}$ ribosomal RNA gene, GenEMBL $\mathrm{AC}$ M11167); 5' primer: bases 45354564; 3' primer: bases 4667-4638; expected PCR fragment: $133 \mathrm{bp}$. COX1 (human mitochondrial genome, GenEMBL AC V00662); 5' primer: bases 6053-6082; 3' primer: bases 6246-6218; expected PCR fragment: 194 bp. 16S (human mitochondrial genome, GenEMBL AC V00662); 5' primer: bases 2852-2878; 3' primer: bases 3107-3079; expected PCR fragment: $256 \mathrm{bp}$. The specificity of the primers was tested by diagnostic restriction cuts of the PCR products.

\section{CLC Standard}

The synthetic RNA was synthesized by RNA polymerase T7 transcription according to the manufacturer's instructions (Böhringer Mannheim, Germany). A linearized bluscript $\mathrm{KS}+$ vector containing a full-length CDNA of CLC was used as template. The cRNA was diluted to $\sim 100 \mathrm{pg} / \mu \mathrm{l}$ in TE $[10 \mathrm{~mm}$ Tris- $\mathrm{HCl}$ ( $\mathrm{pH}$ 7.4), $1 \mathrm{~mm}$ EDTA (pH 8.0)] containing $100 \mathrm{ng} / \mu \mathrm{l}$ tRNA and stored in aliquots.

\section{RNA Extraction}

Total RNA was prepared by the acid phenol method. ${ }^{(10)}$ First, $25-\mu \mathrm{m}$ cyrostat sections $(2,4,6$, and 8 sections per sample for the test series, 5 sections for the training studies) were homogenized in $500 \mu \mathrm{l}$ lysis buffer [solution D in ${ }^{(10)}$ ] containing $10 \mu \mathrm{l}$ of CLC standard and $\sim 2 \mu \mathrm{g}$ Schizosaccharomyces pombe total RNA as carrier. The final pellet was dissolved in $10 \mu \mathrm{H}_{2} \mathrm{O}$ and digested with DNase in $1 \times$ reverse transcription buffer (GIBCO BRL) containing 8 units RNasin (Böhringer Mannheim, Germany) for $30 \mathrm{~min}$ at $37^{\circ} \mathrm{C}$. Then, $90 \mu \mathrm{I} \mathrm{H}_{2} \mathrm{O}$ and $15 \mu \mathrm{l} 2 \mathrm{M}$ sodium acetate ( $\mathrm{pH} 4.0$ ) were added and the solution was extracted with 1 volume each of $\mathrm{H}_{2} \mathrm{O}$-saturated phenol and chloroform. The RNA was ethanol precipitated, washed with $75 \%$ ethanol, and air dried. In some samples, a pellet was visible at this stage.

\section{Planimetry}

Tissue volumes were estimated by planimetry from 2 to $325-\mu \mathrm{m}$ cryostat sections serial to the samples used for RNA extraction. This was done by multiplying the apparent muscle surface with the section thickness.

\section{Reverse Transcription (RT)}

The RNA pellet was dissolved in $10 \mu \mathrm{l}$ $\mathrm{H}_{2} \mathrm{O}$ and reverse transcribed by Superscript RNase H-RT (GIBCO BRL) using random hexamer priming according to the manufacturer's specifications. After $1 \mathrm{hr}$ at $37^{\circ} \mathrm{C}$, the enzyme was inactivated by incubation at $95^{\circ} \mathrm{C}$ for $10 \mathrm{~min}$. Thereafter, the solution was diluted to $200 \mu \mathrm{l}$ with TE, yielding the RT mix used in the PCR.

\section{Reference Samples (RS)}

Reference samples were prepared from 100-200 $\mu \mathrm{l}$ PCR assays run to saturation. The DNAs were phenol extracted and ethanol precipitated. Pellets were dissolved in TE and the concentration of DNA determined spectrophotometrically. Appropriate dilutions were made in $T E$ containing $10 \mu \mathrm{g} / \mathrm{ml}$ tRNA to match the appearance of ethidium bromide-stained PCR signals of the muscle samples.

\section{PCR}

For every primer pair, the optimal $\mathrm{Mg}^{2+}$ concentration and annealing temperature was determined: for $\operatorname{COX} 4,4 \mathrm{~mm}$ $\mathrm{Mg}^{2+}, 70{ }^{\circ} \mathrm{C}$; for COX1, $1.5 \mathrm{~mm} \mathrm{Mg}^{2+}$, $60^{\circ} \mathrm{C}$; for $16 \mathrm{~S}, 28 \mathrm{~S}$, and CLC, $3.5 \mathrm{~mm}$ $\mathrm{Mg}^{2+}, 65^{\circ} \mathrm{C}$. For every PCR run, a master mix was prepared on ice using the $10 \mathrm{X}$ buffer supplied by the manufacturer, 0.4 $\mu \mathrm{M}$ each primer, $20 \mu \mathrm{M}$ each $\mathrm{dNTP}, 0.08$ $\mu \mathrm{Ci} / \mu \mathrm{l}\left[\alpha-{ }^{32} \mathrm{P}\right] \mathrm{dTTP}$, and $1.6 \mathrm{U} / 100 \mu \mathrm{I}$ DynaZyme DNA polymerase (Finnzymes Oy, Finland). Then, $2 \mu \mathrm{l}$ of RT mix (further diluted $1: 10$ for $28 \mathrm{~S}$ rRNA measurements) were pipetted to $0.5-\mathrm{ml}$ Eppendorf tubes on ice and $38 \mu$ l of the master mix plus 2 drops of mineral oil (Sigma) were added (Fig. 1B). In each PCR run, a triplicate reference sample (RS, see above) was amplified in parallel. A control without template was also run each time. Mixtures containing $1 \mu \mathrm{l}$ of two samples each were amplified in parallel during every PCR run to control for systemic differences among samples (see below). The tubes were transferred into the preheated $\left(95^{\circ} \mathrm{C}\right)$ thermocycler (COY, Fröbel Labortechnik Lindau, Germany) and DNA was denatured for 2 min. PCR steps were: denaturation at $95^{\circ} \mathrm{C}$ for $30 \mathrm{sec}$, annealing at the appropriate temperature (see above) for $1 \mathrm{~min}$, and extension at $72^{\circ} \mathrm{C}$ for $30 \mathrm{sec}$. Twentythree cycles were run for $\mathrm{COX} 4 ; 16$ cycles for COX1, CLC, and 28S; and 15 cycles for 16S RNA. After the amplification, 30 $\mu l$ of the reaction mixture was transferred into a new tube to get rid of the mineral oil, and $5 \mu$ was loaded onto a $6 \%$ polyacrylamide gel containing $1 \mathrm{M}$ urea. This was exposed to X-ray films for $\sim 1 \mathrm{hr}$. We have found that $1 \mathrm{~m}$ urea in polyacrylamide gels helps to reduce background. NuSieve agarose gels (FMC) resulted in much higher, nonhomogeneous background radioactivity. Gels were dried between two cellophane sheets (Migros, Switzerland), which greatly facilitated the excision of the bands. The corresponding bands were cut out and the incorporated radioactivity was determined by liquid scintillation counting. The control, without template, served as background, which was subtracted to yield the muscle sample counts. Muscle sample counts were related to the mean of the triplicate RS. Because the RS contain a known amount of DNA, the relative values of the muscle samples could be converted into absolute concentrations.

\section{Statistical Analysis}

Statistical analysis was performed using Systat 5.01 for Windows (Systat Inc.). The RNA contents of the muscle samples were expressed as the ratio of RNA to CLC. The coefficients of error of these ratios were calculated as follows: $\mathrm{ce}_{\text {ratio }}=$ SQRT $\left(\mathrm{Ce}_{\mathrm{clc}}^{2}+\mathrm{Ce}_{\mathrm{rna}}^{2}\right)$.

\section{RESULTS}

\section{Overview of the Approach}

A schematic representation of our apprach is given in Figure 1A. Total RNA was extracted from muscle cryostat sections, the volume of which was estimated by planimetry of sections serial to them. The RNA extractions and the sub- 
A

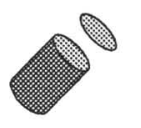

muscle biopsy

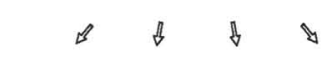

$\begin{array}{llll}2 & 4 & 6 & 8 \\ 8 & 3 & & \end{array}$

ㄴ.
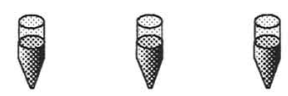

Lysis buffer containing

10 ul CLC standard
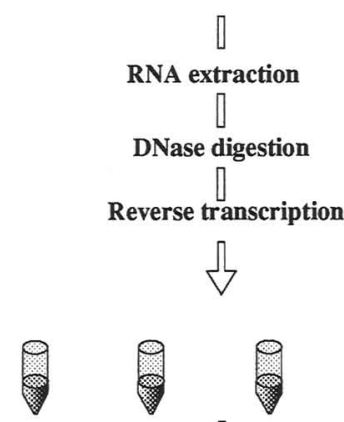<smiles>C1=CC=C1</smiles><smiles>C1CCCC1</smiles>

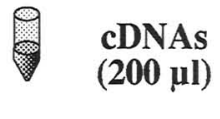

* 4-7 runs of PCR quantitation for each RNA

* normalization to PCR-quantitated CLC-standard

* normalization to tissue volume used for RNA extraction

B

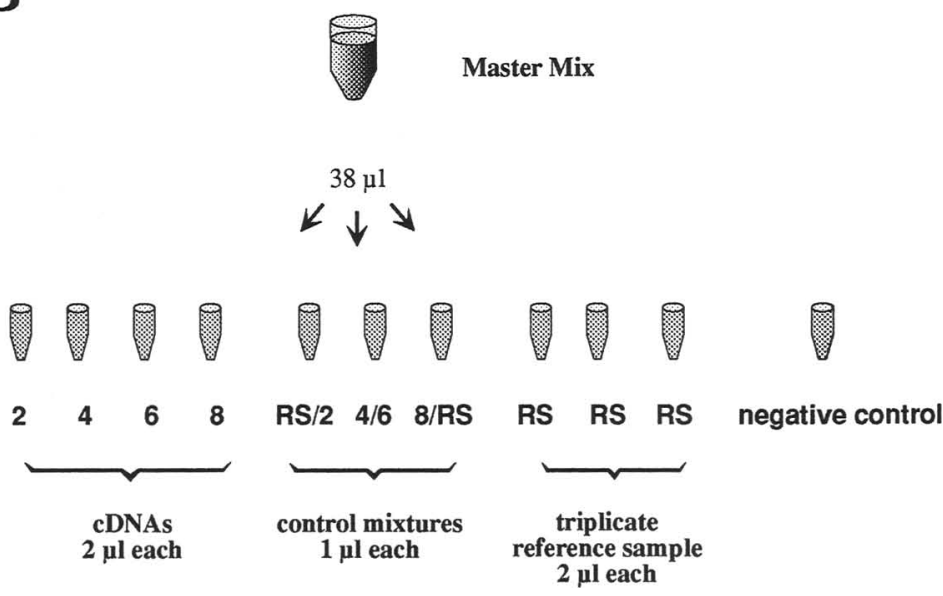

FIGURE 1 (A) Schematic representation of quantitative RT-PCR approach. Total RNA is extracted from 2,4,6, or 8 muscle cryostat sections. After DNase digestion and RT, 4-7 runs of PCR quantitation (as indicated in $\mathrm{B}$ ) are performed. The values are normalized to the amount of tissue used for RNA extraction and to the recovery of the synthetic CLC RNA standard. (B) Set up of a single PCR run. For each run, a master mix was prepared and aliquots were added to CDNAs, control mixtures (containing half the volume of two samples each), reference samples (containing a known amount of template DNA), and negative control. See text for details.

sequent RTs were normalized by an unrelated cRNA (CLC), which was added at the beginning and quantified separately afterwards. Quantitation of individual cDNAs was achieved by parallel amplifications of samples together with RSs, which contain a known amount of tem- plate DNA (Fig. 1B). Control mixtures containing half the volume of two samples each were run in parallel to control for systemic differences among samples. Several repetitions of PCR runs reduced the problem of stochastic variation in the efficiency of the PCR.

\section{Determination of the Exponential Phase of the PCR}

Quantitative PCR without internal standards, such as ours, requires that the reaction is stopped while it is still in the exponential phase (plateau effect). ${ }^{(11)}$ The kinetic behavior of the process was assessed by incorporating ${ }^{32}$ P-labeled nucleotides (Fig. 2). Aliquots of the reaction mixture were withdrawn after successive cycles and separated on a $6 \%$ polyacrylamide gel. The gels were stained with ethidium bromide. Thereafter, the incorporated radioactivity was measured by scintillation counting. The comparison of the ethidium bromide stain with the PCR kinetics shows that the first 3-4 cycles that yield visible bands on an ethidium bromide stain still represent the exponential phase of the reaction (Fig. 2). Thus, it is easy to determine the range where quantitative PCR has to be performed: We determine the particular cycle in which the sample with the highest concentration of template is just visible on the ethidium bromide gel. It assures that all reactions are in the exponential phase. This analysis had to be repeated for every new primer pair.

\section{Standardization}

The limited amount of starting material does not allow to determine the amount of RNA used for reverse transcription, which is often used to standardize RTPCR. ${ }^{(5,6,12-14)}$ Housekeeping gene products such as aldolase ${ }^{(15,16)}$ or $28 \mathrm{~S}$ rRNA $^{(17)}$ have been used to account for differences in input RNA. However, no true housekeeping gene has been established so far in skeletal muscle. We have standardized our samples to the volume of tissue used for RNA extraction (by planimetry of serial sections). Alternatively, the protein content of the tissue homogenates can be measured. We have done this in $8 \mu$ l of the initial $500-\mu l$ homogenates of the samples from the trained and untrained subjects using the amidoblack method. ${ }^{(18)}$ The protein concentrations determined (mean: 132 $\mu \mathrm{g}$; range $57-371 \mu \mathrm{g}$ ) closely correlated with the volumes of the muscle samples (mean: $0.78 \mathrm{~mm}^{3}$; range: $0.38-2.36$ $\mathrm{mm}^{3}$; data not shown).

To account for variations in the recovery of extracted RNA $(\sim 40 \%$, data not shown) and the variable efficiency of the 


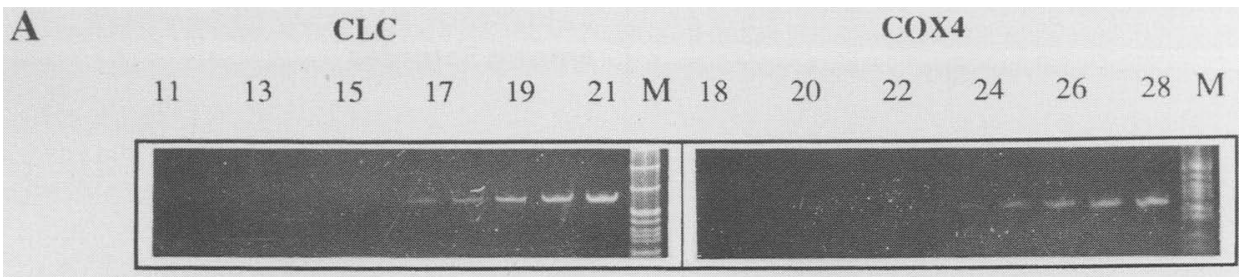

B

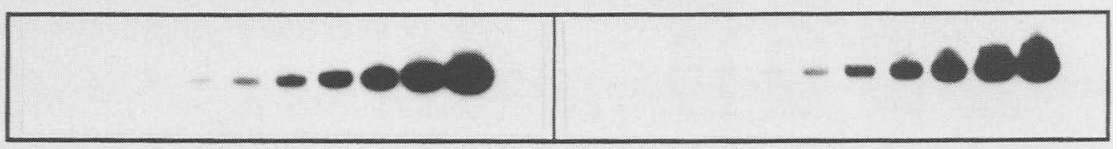

C

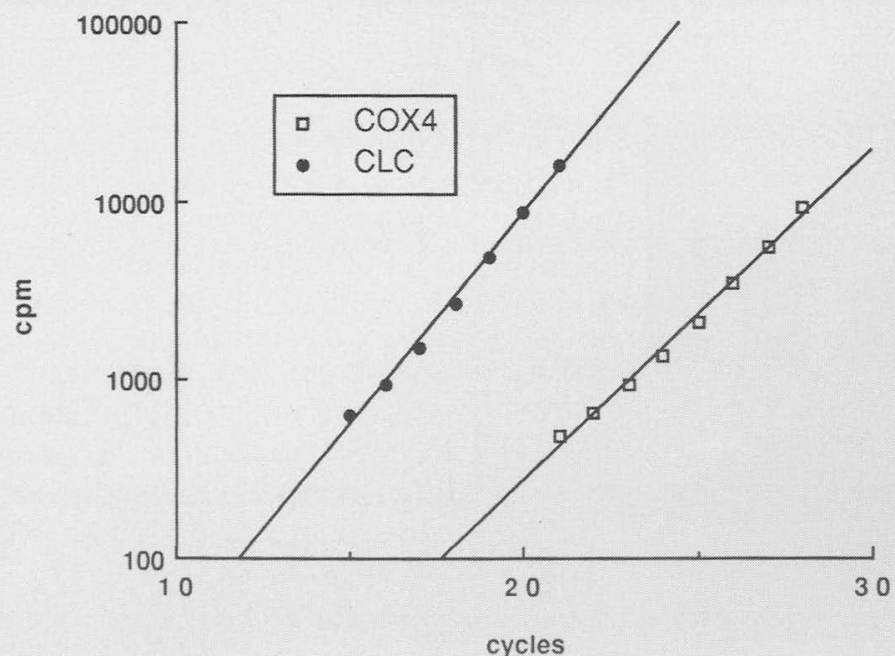

FIGURE 2 Comparison of PCR kinetics with ethidium bromide staining of COX4 and CLC templates. Aliquots were withdrawn from the reaction after consecutive cycles and separated on polyacrylamide gels. $(A)$ Ethidium bromide-stained gels. Cycle numbers are indicated. $M=$ molecular size marker. $(B)$ Autoradiograms of the gels in A. (C) Plot of incorporated radioactivity at the respective cycles.

subsequent RT step, a constant amount of a synthetic cRNA (CLC) was added to the lysis buffer before homogenization of the muscle samples. This CLC was quantified separately by PCR as de-

scribed below. The concentrations of the different RNAs were normalized to the amount of CLC obtained. Such an unrelated CRNA is universally applicable. However, it precludes the absolute quan-

TABLE 1 RNA Concentrations Measured in Different Numbers of Cryostat Sections

\begin{tabular}{lllll}
\hline Sections & $\begin{array}{l}28 \mathrm{~S} \\
\text { ng/section }\end{array}$ & $\begin{array}{l}\text { 16S } \\
\text { ng/section }\end{array}$ & $\begin{array}{l}\text { COX1 } \\
\text { pg/section }\end{array}$ & $\begin{array}{l}\text { COX4 } \\
\text { pg/section }\end{array}$ \\
\hline 2 & $6.40 \pm 2.63$ & $0.82 \pm 0.22$ & $2.63 \pm 0.80$ & $0.78 \pm 0.19$ \\
4 & $8.15 \pm 2.60$ & $0.86 \pm 0.22$ & $1.85 \pm 0.54$ & $0.81 \pm 0.21$ \\
6 & $7.38 \pm 2.41$ & $1.09 \pm 0.29$ & $1.99 \pm 0.52$ & $0.80 \pm 0.20$ \\
8 & $14.25 \pm 4.99$ & $1.25 \pm 0.32$ & $3.82 \pm 1.12$ & $1.02 \pm 0.26$ \\
Mean & $9.04 \pm 3.54$ & $1.00 \pm 0.20$ & $2.57 \pm 0.90$ & $0.85 \pm 0.12$ \\
\hline
\end{tabular}

All values are means \pm S.E., except for mean ( \pm S.D.). titation of different RNAs, as their RT efficiency might differ from the standard. Furthermore, it is hardly possible to get a good estimate of the exact number of full-length molecules in a cRNA sample, which would be important to determine the fraction of recovered and reverse transcribed molecules.

The concentrations of the different CDNAs by PCR were obtained by a parallel amplification of a so-called RS containing a known amount of DNA. Thus, cDNAs (as well as genomic DNA) can be quantitated this way in absolute terms. The RSs are simply products prepared from previous PCRs. Therefore, the availability of cDNAs is not restricting and no cloning steps are needed. Any RNA, whose sequence or part of it is known, can be quantitated.

The RNA concentrations in this paper represent CDNA concentrations normalized by CLC are relative concentrations in a strict sense. They are given in absolute terms for reasons of simplicity, however.

\section{PCR Quantitation}

In our test series of $2,4,6$, and 8 muscle sections, four different RNAs were quantitated: 16S rRNA, 28S rRNA, COX4 mRNA, and COX1 mRNA (Table 1). Five separate PCR runs were performed for each cDNA species. A master mix was prepared for all the samples of each run. During every PCR run, an RS with a known amount of DNA was amplified separately in triplicate. The radioactivity incorporated in each sample was related to this RS and, thus, converted into absolute amounts of template DNA present at the beginning of the reaction (Fig. 3). A sample without template served as a negative control and as a measure of background radioactivity.

The reproducibility of our quantitation is illustrated in Table 2 . The variation among triplicate RS measurements in individual experiments was relatively small (mean C.v. \pm s.D.: $0.078 \pm 0.04$, $n=26$ ), whereas the amount of PCR product in relation to the reference sample varied much more from PCR run to PCR run (mean c.v. \pm S.D.: $0.34 \pm 0.17$, $n=26$ ). Small, uncontrollable differences between the master mixes are the most likely source of the latter variations. The approximate proportional values for the four RNAs shown in Figure 3 


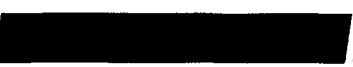

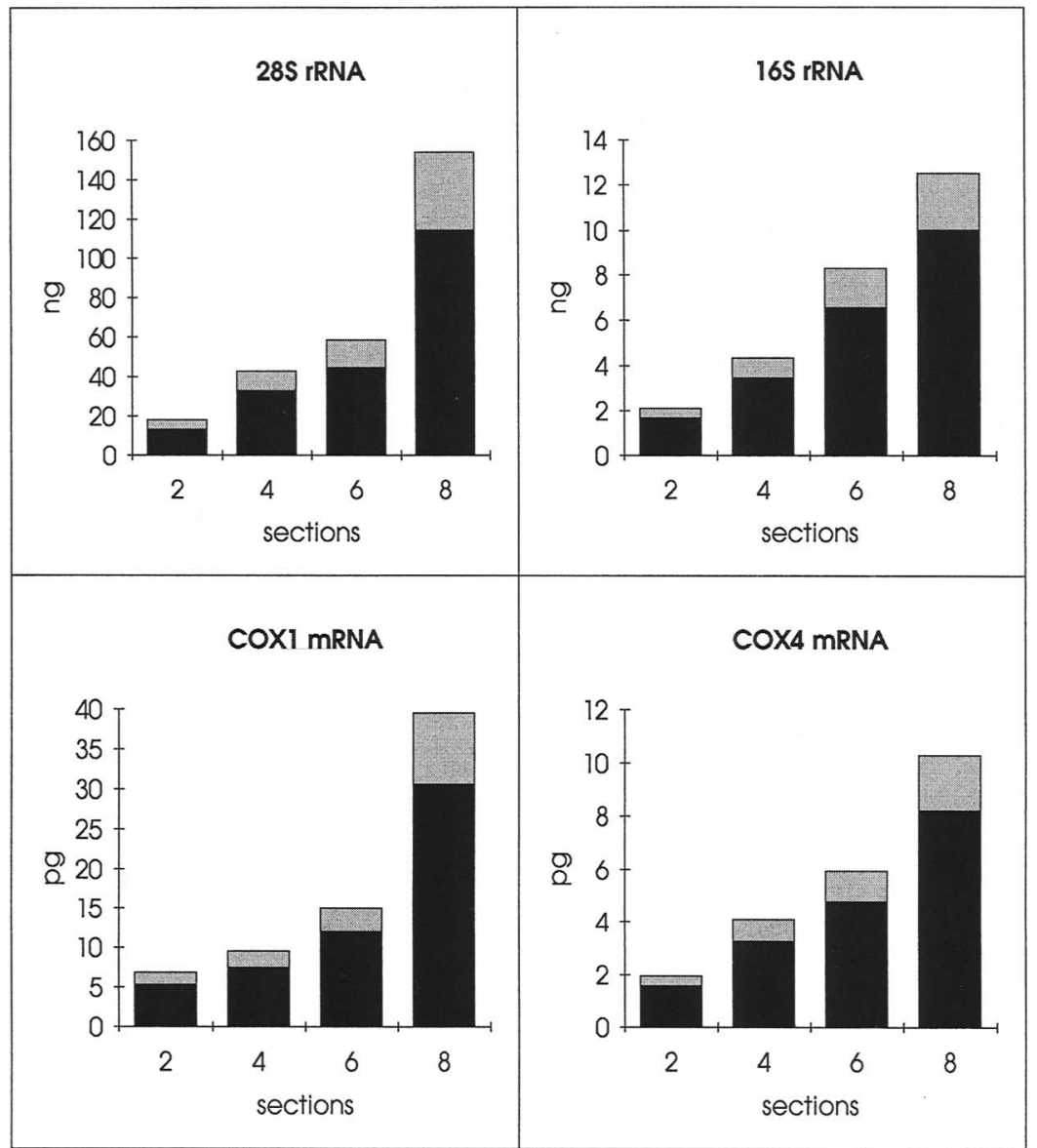

FIGURE 3 Amount of different RNAs in cryostat sections from the same muscle as determined with quantitative RT PCR. Standard errors are shown in shaded bars. reflect the increasing amount of input tissue. Good proportions between amount of tissue used and RNA content have been found for COX4 and $16 \mathrm{~S}$ RNA; the method was less precise for $28 \mathrm{~S}$ and COX1 RNA. The range of the variations (c.v. 0.15-0.53) for the different primer pairs indicate that some are less affected by the variability of master mixes than others.
TABLE 2 Variances of RT-PCR Quantitation

\begin{tabular}{lccc}
\hline Template & c.v. among PCR runs ${ }^{\mathrm{a}}$ & c.v. within PCR runs $^{\mathrm{b}}$ & c.v. between samples $^{c}$ \\
\hline COX1 & $0.341 \pm 0.08(5)$ & $0.044 \pm 0.039(5)$ & 0.348 \\
COX4 & $0.150 \pm 0.04(5)$ & $0.122 \pm 0.076(5)$ & 0.135 \\
28S & $0.530 \pm 0.10(5)$ & $0.028 \pm 0.013(5)$ & 0.387 \\
16S & $0.189 \pm 0.10(4)$ & $0.088 \pm 0.038(4)$ & 0.200 \\
CLC & $0.505 \pm 0.15(7)$ & $0.106 \pm 0.038(7)$ & - \\
\multicolumn{1}{c}{ Mean } & $0.340 \pm 0.17(26)$ & $0.078 \pm 0.04(26)$ & $0.268 \pm 0.12$ \\
\hline
\end{tabular}

All values are means \pm S.D.

aThe mean of the c.v. of the four samples $(2,4,6$, and 8 sections) among the 4-7 PCR runs performed for each RNA species. This is a measure for the variation between different PCR runs. The numbers of PCR runs are in parentheses.

'The mean of the c.v. of the triplicate MS measurements. This is a measure for the variation within a given PCR run. The numbers of PCR runs are in parentheses.

'The c.v. of the RNA concentrations of the four samples $(2,4,6$, and 8 sections), calculated per unit section as also illustrated in Table 1 . This is a measure for the variation of our overall approach.

\section{Control for Systemic Differences among Samples}

To detect systemic differences among the different samples caused by the presence of inhibitors or stimulators, ${ }^{(19)} \mathrm{ev}$ ery sample in each PCR run was mixed with another (half volume of each) and amplified in parallel (Fig. 1B). RS was mixed with the 2-section sample, the 4-section sample with the 6-section sample, and the 8-section sample again with the RS. The amount of PCR product should therefore be the mean of the corresponding samples. Figure 4 shows, within the error of the method, that the correct values were found for the mixes, indicating no differences among the samples.

\section{Precision}

Our series of samples with increasing amounts of input tissue $(2,4,6$, and 8 sections) gives an indication to the precision of the approach. It can be deduced from the RNA values per unit section, which are illustrated in Table 1 . For a given RNA, this parameter should be constant among the different amounts of input tissue. The variations among the samples are shown in Table 2 . They range between $13.5 \%$ and $38.7 \%$, with a mean of $26.8 \%$.

\section{COX4 mRNA in Endurance Trained and Untrained Subjects}

We have applied this new approach to the analysis of gene expression in human skeletal muscle in response to exercise training. The content of COX4 mRNA in $m$. vastus lat. from four highly trained endurance runners was compared with four untrained subjects. It was found to be 1.83-fold higher in the endurance-trained subjects (4.82 versus $2.63 \mathrm{pg} / \mathrm{mm}^{3}$ tissue). This corresponds with the differences in mitochondrial content between these two groups. Stereological analysis of these biopsies revealed a twofold higher mitochondrial volume density (fraction of cytoplasm occupied by mitochondria) for the trained subjects $(8.2 \pm 0.92 \%$ versus $4.1 \pm 0.72 \%$, data not shown). Because the amount of cytochrome $c$ oxidase protein is proportional with the mitochondrial volume density, ${ }^{(20)}$ the RNA concentrations found closely match the expected protein values. 


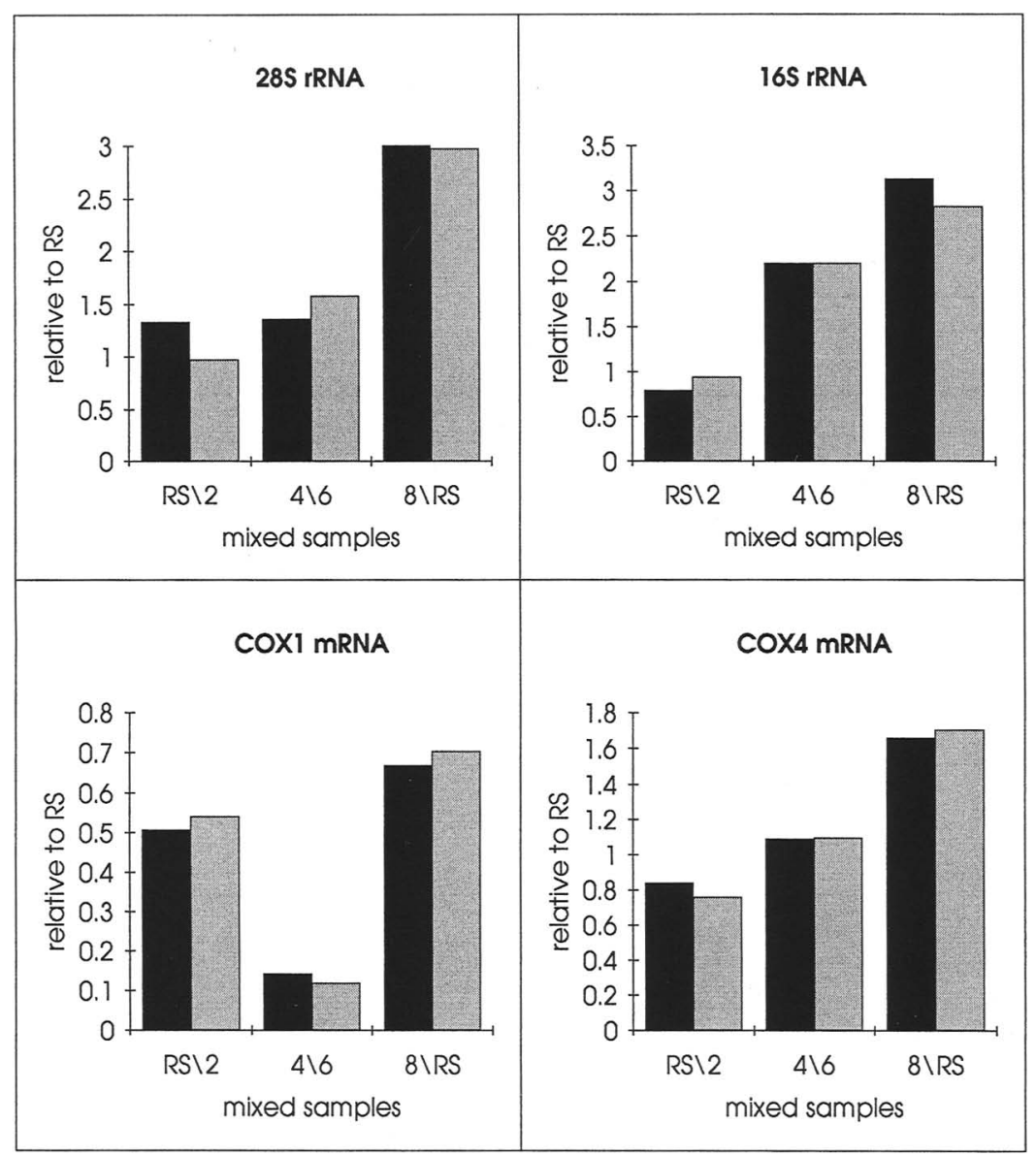

FIGURE 4 Control mixtures for PCR amplifications. In each PCR run, half volumes of two samples each were mixed and amplified in parallel with these. Black bars represent the obtained amount of incorporated radioactivity in the mixture samples relative to RSs. Shaded bars represent the expected values calculated from the two samples amplified separately. RS/2: mixture of respective RS and 2-section sample. 4/6: mixture of 4 -section sample and 6-section sample. 8/RS: mixture of respective RS and 8-section sample. Values are means of five measurements.

\section{DISCUSSION}

In the study of the effects of exercise training on gene expression in human skeletal muscle, we are faced with the problem of detecting small differences in RNA concentrations in minute tissue samples from heterogeneous populations. We have combined and modified currently available PCR methodology to an approach that allows to determine the concentration of several RNAs in a large number of samples. It is characterized by the independent standardization of the individual steps and ignores attempts to control for the efficiency of the PCR. Precision is achieved by multiple measurements of several samples.

We have determined the precision of our approach for a narrow linear range, where the RNA concentrations in our samples differ by no more than one or- der of magnitude. It is represented in the variation of the concentration of the different RNAs per section (Table 1). As can be deduced from the coefficients of variation among samples in Table 2, for all the transcripts tested, a less than twofold difference in input RNA can be detected. Assuming two times the coefficient of variation to be the detectable limit, differences betwen $27-88 \%$ (mean 54\%) should be discernible. This is comparable to or better than previously published methods. ${ }^{(12,15,21)}$ It is noteworthy that there is good correlation between the variation of the RNA prep/RT (c.v. among samples in Table 2) and the variation of the PCR for each RNA (c.v. among PCR runs in Table 2). Thus, the nature of the nucleic acid sequence seems to determine the susceptibility to small changes in the environment dur- ing both processes. Likely, the precision of our method therefore depends on the RNA species studied.

We have optimized our approach to minimize work and still achieve high precision. It is based on four independent RNA preps/RTs, either on four measurements of one sample (Table 1), or on one measurement of four samples (trained versus untrained). In our routine procedure, each PCR reaction is repeated from four to five times. In many cases, fewer runs may be adequate: We have found that three PCR runs for the CLC standard and a single PCR run for each of the RNAs is sufficient to achieve equivalent coefficients of variation in the test series of two to eight sections, and slightly different proportions between trained and untrained subjects. Instead of 1.83 times higher values for the trained group (when five PCR runs were performed for COX4 and CLC each), we found values between 1.6-2.2 for each of the five individual COX 4 PCR runs (data not shown).

In conclusion, the statistical approach to PCR quantitation presented in this paper is versatile. It allows the quantitative determination of just about any RNA or DNA, whose sequence is known and is especially suited in cases where the analysis of multiple RNA species in numerous samples is required.

\section{ACKNOWLEDGMENTS}

We thank Drs. John Lucocq and Luis $M$. Cruz-Orive for helpful discussions, Drs. Thierry Soldati and Jean-Cleaude Perriard for providing us with the chicken myosin light chain clone, and Barbara Krieger for technical help. This work was supported by the Swiss National Science Foundation Grant. Nr. 31-28821.90.

\section{REFERENCES}

1. Booth, F.W. and D.B. Thomason. 1991. Molecular and cellular adaptation of muscle in response to exercise: Perspectives of various models. Physiological Rev. 71: 541-585.

2. Saiki, R.K., S. Scharf, F. Fallona, K.B. Mullis, G.T. Horn, H.A. Erlich, and N. Arnheim. 1985. Enzymatic amplification of $\beta$-globin genomic sequences and restriction site analysis for diagnosis of sickle cell anemia. Science 230: 1350-1354.

3. Gilliland, G., S. Perin, K. Blanchard, and H.F. Bunn. 1990. Analysis of cytokine mRNA and DNA: Detection and quantita- 
tion by competitive polymerase chain reaction. Proc. Natl. Acad. Sci. 87: 27252729.

4. Wiesner, R.J., J.C. Ruegg, and I. Morano. 1992. Counting target molecules by exponential polymerase chain reaction: Copy number of mitochondrial DNA in rat tissues. Biochem. Biophys. Res. Comm. 183: 553-559.

5. Wang, A., M.V. Doyle, and D.F. Mark. 1989. Quantitation of mRNA by the polymerase chain reaction. Proc. Natl. Acad. Sci. 86: 9717-9721.

6. Chelly, A., D. Montarras, C. Pinset, Y. Berwald-Netter, and I.-C. Kaplan. 1990. Quantitative estimation of minor mRNAs by cDNA-polymerase chain reaction. Application to dystrophin mRNA in cultured myogenic and brain cells. Eur. J. Biochem. 187: 691-698.

7. Ferre, F. 1993. Quantitative or semi-quantitative PCR: Reality versus myth. $P C R$ Methods Applic. 2:1-9.

8. Clementi, M., S. Menzo, P. Bagnarelli, A. Manzin, A. Valenza, and P.E. Varaldo. 1993. Quantitative PCR and RT-PCR in virology. PCR Methods Applic. 2: 191-196.

9. Nedelman, J., P. Haegerty, and C. Lawrence. 1992. Quantitative PCR with internal controls. Comput. Applic. Biosci. 8: $65-70$.

10. Chomczynski, P. and N. Sacchi. 1987. Single-step method of RNA isolation by acid guanidinium thiocyanate-phenol-chloroform extraction. Anal. Biochem. 162: 156159.

11. Sardelli, A.D. 1993. Plateau effect-Understanding PCR limitations. Amplifications 9: 1-5.

12. Becker-Andre, M. and K. Hahlbrock. 1989. Absolute mRNA quantification using the polymerase chain reaction (PCR). A novel approach by a PCR aided transcript titration assay (PATTY). Nucleic Acids Res. 17: 9437-9446.

13. Murphy, L.D., C.E. Herzog, J.B. Rudick, A.T. Fojo, and S.E. Bates. 1990. Use of the polymerase chain reaction in the quantitation of mdr-1 gene expression. Biochemistry 29: 10351-10356.

14. Noonan, K.E., C. Beck, T.A. Holzmayer, J.E. Chin, J.S. Wunder, I.L. Andrulis, A.F. Gazdar, C.L. Willman, B. Griffith, D.D. Von Hoff, and I.B. Roninson. 1990. Quantitative analysis of MDR1 (multidrug resistance) gene expression in human tumors by polymerase chain reaction. Proc. Natl. Acad. Sci. 87: 7160-7164.

15. Hoof, T., J.R. Riordan, and B. Tuemmler. 1991. Quantitation of mRNA by the kinetic polymerase chain reaction assay: A tool for monitoring P-glycoprotein gene expression. Anal. Biochem. 196: 161-169.

16. Chelly, J., J.-C. Kaplan, P. Maire, S. Gautron, and A. Kahn. 1988. Transcription of the dystrophin gene in human muscle and non-muscle tissues. Nature
333: 858-860.

17. Rappole, D.A., A. Wang, D. Mark, and Z. Werb. 1989., Novel method for studying mRNA phenotypes in single or small numbers of cells. J. Cell. Biochem. 39: 111.

18. Schaffner, W. and C. Weissmann. 1973. A rapid, sensitive and specific method for the determination of protein in dilute solution. Anal. Biochem. 56: 502-514.

19. Yang, B., R. Yolken, and R. Viscidi. 1993. Quantitative polymerase chain reaction by monitoring enzymatic activity of DNA polymerase. Anal. Biochem. 208: 110116.

20. Schwerzmann, K., H. Hoppeler, S.R. Kayar, and E.R. Weibel. 1989. Oxidative capacity of muscle and mitochondria: Correlation of physiological, biochemical, and morphometric characteristics. Proc. Natl. Acad. Sci. 86: 1583-1587.

21. Ito, H., S.C. Miller, H. Akimoto, S.V. Torti, A. Taylor, M.E. Billingham, and F.M. Torti. 1991. Evaluation of mRNA levels by the polymerase chain reaction in small cardiac tissue samples. /. Mol.Cell. Cardiol. 23: $1117-1125$.

Received October 29, 1993; accepted December 16, 1993. 


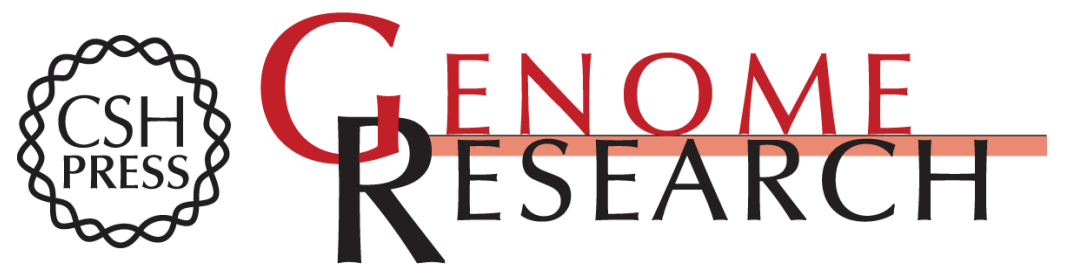

\section{An efficient polymerase chain reaction approach for the quantitation of multiple RNAs in human tissue samples.}

A Puntschart, K Jostarndt, $\mathrm{H}$ Hoppeler, et al.

Genome Res. 1994 3: 232-238

References This article cites 21 articles, 5 of which can be accessed free at: http://genome.cshlp.org/content/3/4/232.full.html\#ref-list-1

License

Email Alerting

Receive free email alerts when new articles cite this article - sign up in the box at the Service top right corner of the article or click here.

\section{Affordable, Accurate Sequencing.}

To subscribe to Genome Research go to: https://genome.cshlp.org/subscriptions 